spending, is likely to continue ratcheting down how much it pays doctors, with insurers following suit. The prospect for major federal reform of medical care during the next four years, whether under Mr Clinton or Mr Bush, is poor.

JOHN C ROBERTS

Assistant Professor,

Johns Hopkins University,

Baltimore, Maryland 21224

USA
1 Clinton B. The Clinton health care plan. N' Engl F Med 1992:327:804-7.

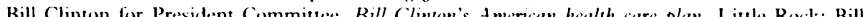
Clinton for President Committec, 1992.

3 Enthoren AC Commentary: measuring the candidates on health care. $N$ lingl f . Hed 1992; 327:807-9.

+ Reinhardt UE. Commentary: measuring politics and the health care system. $N$ lingl f Med 1992:327:809-11.

5 America's parasite economy: the papers that ate America. Ecomomist 1992 October 10-16:21-4.

6 Freudenheim M. Business and health: partisan dectors in campaign '92. New York Times 1992 Sept $15: 1) 2$

Labaton S. Health industry gives freely in election. Nea Y'ork Times 1992 October 13:A21.

8 American College of Phisicians. Universal insurance for American health care: a proposal of the American College of Phrsicians. Ann Intern Med 1992;117:512-9.

9 Litan RE. Porot medicine for Climen Nene Vork Times 1992:7:021.

\title{
Australia's national health strategy
}

\author{
Medicare under the microscope
}

Two years ago Australia embarked on an ambitious review of all aspects of its health care system. On its packed agenda are the distribution of health care costs and their impact on individual people and families, factors creating demand for medical services, and options to contain costs while maintaining quality and access, particularly in public hospitals. The review has also to consider the role of the private sector and ways of better integrating community and preventive services with the rest of the health care system. Its terms of reference also list the effects of financial and organisational arrangements on the delivery of health care, and the supply of and demand for health workers. Once decided, a formal strategy will presumably form part of the federal Labor party's health policy.

Whatever the outcome of the review it has been assumed that at least part of Australia's system of universal health insurance (Medicare) will stay. Medicare is funded out of general revenue and meets half the costs of free public hospital care, with states and territories providing the other half. By directly reimbursing doctors Medicare also finances most general and specialist medical services outside hospital. Spending on "hospital Medicare" is under government control and hence capped. "Medical Medicare" is not, the only limit on spending being agreed levels of government reimbursement for individual services with no controls on their volume.

Two out of five Australians have private health insurance, which allows them greater choice of doctor and pays for better hotel services in public hospitals and much of the cost of care in private hospitals. (These usually offer less technically sophisticated services than public hospitals.) This variety of funding sources-federal, state, and private-complicates the financial management of health care and makes integrating services more difficult. It also encourages cost shifting: hospital managers, responsible to their state or territory, tend to encourage doctors to get patients out of hospitals into the community, where the commonwealth pays for services (such as those provided by family practitioners).

How much progress has been made in setting Australia's "national health strategy?" So far options are being explored: the review has published 10 background papers and four issues papers ${ }^{1-1+}$ and interest groups have been consulted widely. The effects of the review may be clearly seen in current proposals for renegotiating the next Medicare agreement, to run from 1993 to 1998 . It conflates the 26 separate agreements between the commonwealth and the states now governing health care and the care of elderly people into six "broad band" programmes: public hospitals, pharmaceuticals, non-inpatient medical specialist and diagnostic services, primary health and community care, mental health, and small rural communities.

The new Medicare agreement requires future health services to be geared to achieve explicit health outcomes. Current initiatives in several states, including the largest (New South Wales), will fit well with this, as will a national review of goals and targets for Australia's health, which builds on earlier work by the Better Health Commission and the National Better Health Programme. ${ }^{15} 16$

In Australia fiscal power is concentrated at the centre (the federal government). Political changes there can result in considerable changes in medical practice more easily than, say, in Canada. ${ }^{17}$ With health care so politicised and its financing so centralised, the new strategy, originated by a Labor minister, has its best chance of success if endorsed by the current Labor government. What would happen after a change of government is uncertain. The draft health policy published last year by the conservative opposition made no specific reference to the strategy. Instead its solutions to the dilemmas of health care policy depended on substantial government encouragement (subsidy) of private health insurance.

Political concerns aside, the strategy documents are a leap forward in seeking public discussion about how Australia spends the $8 \%$ of its gross domestic product allocated to health care. Asking the questions and stimulating the debate can only be good for the health of the public.

STEPHEN R LEEDER

Professor of Public Health and Community Medicine,

University of Sydney,

Sydney,

New South Wales 2006

Australia

General Superintendent,

JENNIFER ALEXANDER

Westmead Hospital,

New South Wales 2145

Australia

1 Macklin J. The National Health Strategy: setuing the agenda for change. Background paper I. Melbourne: National Health Strategy, 1990.

Decble J. Medical services through Medicare. Background paper 2. Melbourne: National Health Strategy, 1991 .

McClelland A. In fair health? Equity and the health system. Background paper 3. Melbourne: National Health Strategy, 1991

4 Willcox S. A healthy risk? Use of private health insurance. Background paper 4. Melbourne: National Health Strategy, 1991

5 Richardson J. The effects of consumer co-pavments in medical care. Background paper 5. Melbourne: National Health Strategy, 1991

6 Deeble J, Lewis-Hughes P. Directions for pathologv. Background paper 6. Melbourne: National Health Strategy, 1991

McClelland A. Spending on health. The distribution of direct payments for health and medical services. Background paper 7. Melbourne: National Health Strategy, 1991.

8 Harvey R. Making it better: strategies for improving the effectiveness and quality of health services in Australia. Background paper 8. Melbourne: National Health Strategy, 1991.

9 Dooland M. Improving dental health in Australia. Background paper 9. Melbourne: National Health Strategy, 1992. 
10 Keith A A study of hospital outpatient and emersency department sersices. Backaround puper 10 . Melbourne: National Health Strategv, 1992.

I National Health Strategv. The Australian health jigsaze integration of health care delivery. Issues paper 1. Melbourne: National Health Strategy, 1991

12 National Health Strategy. Hospital services in Australia access and financing. Issues paper 2. Melbourne: National Health Strategy, 1991.

13 National Health Strategy. The future of general practice. Issues paper 3. Melbourne: National Health Strategy, 1992
14 National Health Strategv. Issues in drug use in Australia. Issues paper 4. Melbourne: National Health Strategy, 1992.

15 Better Health Commission. Looking foresard to hetter health. Iols I and 2. Canberra: Australian Government Publishing Service, 1986.

16 Health Targets and Implementation (Health for All) Committee. Health for all A ustralians. Report to Australian health ministers. Canberra: Australian Government Publishing Service, 1988.

17 Gray G. Federalism and health policy: the dezelopment of health svstems in Canada and Australia. Toronto: University of Toronto Press, 199

\title{
Drugs and exercise testing
}

\author{
Consider the reason for the test
}

"Should I take my tablets before the test?"- a common question, but what should be the response in the context of exercise testing and coronary artery disease? Many drugs may substantially affect a patient's exercise capacity, and antianginal drugs in particular may influence many end points assessed during exercise testing. Despite this no consensus exists on whether exercise testing should be performed in the presence or absence of drugs. ${ }^{12}$

Several studies have confirmed the exercise test as a valuable tool in the assessment and prognosis of coronary stenosis. ${ }^{3}$ Although antianginal treatment increases exercise tolerance and decreases symptoms, few data exist on whether it modifies the risk of myocardial infarction in patients with chronic stable angina. The importance of "silent ischaemia" is much debated, but exercise induced ST changes without symptoms are no longer considered to be grounds for therapeutic complacency. ${ }^{+}$It could be argued that all patients should be exercised first off drugs to objectively assess symptoms and risk and then again when they are symptomatically stable on drugs. Patients should then be referred for further investigation on the basis of the first exercise test, with the urgency of referral being based on the second test.

The original studies of the prospective value of exercise testing in chronic stable angina did not exclude patients treated with $\beta$ blockers; the results were valid irrespective of $\beta$ blocker use. $\beta$ Blockers reduce mortality after myocardial infarction, but the use of exercise testing to establish prognosis after myocardial infarction was investigated largely in the absence of $\beta$ blockade. Such treatment might be expected to increase the sensitivity of exercise testing (the probability of a positive test result in those patients with a positive diagnosis) but to decrease its specificity (the probability of a negative test result in those patients with a negative diagnosis). Furthermore, the prognostic implication of a positive exercise test result rendered negative by drug treatment is unknown, ${ }^{\gamma}$ although better short term outcome was noted in a preliminary study of patients in whom these changes were found on exercise radionuclide ventriculography. ${ }^{8}$

In exercise tests used to investigate chest pain the diagnostic yield will be greatest without the confounding effects of antianginal drugs, which should be stopped at least five half lives before the test. For patients presenting with angina who are already taking drugs a baseline test during treatment will go some way toward identifying those at highest risk, while repeating the test off treatment in those who originally tested negative may establish the usefulness of the electrocardiographic aspect of the exercise test in further follow up. Testing the response to specific treatments (for example, angioplasty) should be performed under stable therapeutic conditions. Exercise testing to establish prognosis after myocardial infarction is best undertaken in the absence of calcium antagonists and nitrates. Whether $\beta$ blockade alters the prognostic reliability of a negative result remains unknown, and long term trials are needed. ${ }^{9}$
The withdrawal of drugs causes much concern. If patients experience frequent exertional angina then an exercise test is unlikely to yield further diagnostic information. These patients require further investigation, the urgency of which may be assessed by an exercise test on drugs if the angina is infrequent. Antihypertensive drugs complicate the situation because of their antianginal effects - a positive test result on drugs provides useful information, but a negative result does not, particularly if accompanied by repolarisation abnormalities in the resting electrocardiogram. Other drugs, including digoxin, flecainide, and amiodarone, may interfere with the electrocardiographic interpretation of an exercise test (particularly the lateral ST segments, which are notoriously labile in the presence of digoxin). "Therapeutic difficulty" should be considered an indication for early catheterisation.

Regardless of the problems caused by antianginal drugs in interpreting results of exercise tests, the limitations of these tests in coronary artery disease in general should not be forgotten. Even in patients with clinically important disease up to one in five tests may yield negative results. Exercise testing identifies fixed high grade stenoses, but the risk of infarction is also a function of the number of stenoses, regardless of severity. In common with coronary angiography, exercise testing produces little information about the stability of atheromatous plaque: substantial numbers of patients develop coronary thrombosis with stenosis of less than $50 \%$.

Exercise tests should be requested and interpreted in the light of these limitations if scarce resources are to be used most effectively.

TERRI MILLANE Cardiology Registrar

DAVID WARD

Regional Cardiothoracic Unit, Consultant Cardiologist

St George's Hospital, London SW17 9QT

1 Lim R, Dymond D). Viewpoint: Should antianginal medication be stopped before exercise testing Lancet 1992;340:161-2.

Muir KW, Rodger JC, De Bono JS, McDonald H, Irving JD. Drugs and the exercise test. B.M. 1992;305:808-9.

3 Schlant R, Blomquist C, Brandenburg R, DeBusk R, Ellestad MH, Fletcher (GF. Guidelines for exercise testing. A report of the joint American College of Cardiology/American Hear Association task force in assessment of cardiovascular procedures (subcommittec on exercise testing). Circulation 1986;74:653-67A.

+ Nyman I, Larsson H, Areskog M, Wallentin L. The predictive value of silent ischemia at an exercise test before discharge after an apisode of unstable coronary artery disease. RISC Sudy Group Am Hearl 7 1992:123:324-31.

5 MeNeer F, Margolis J, Lee K, Kisslo JA, Peter RH, Kong Y. The role of the exercise test in the evaluation of patients for ischemic heart disease. Circulation 1978;57:64-70.

6 Weiner D, Rvan T, McCabe C, Chaitman BR, Sheffield LT, Ferguson JC. Prognosicic importance of a clinical profile and exercise test in medically treated patients with coronary artery disease. of a clinical profile and exercise

Murray D, Tan L, Salih M, Weissberg P, Murray R. Does beta adrenergic hlockade influence the prognostic implications of post-myccardial infarction exercise testing? Br Heart 7 1988;60:47+-9. Lim R, Dyke L, Dymond D. Effect on prognosis of abolition of exercise-induced painles myocardial ischemia by medical therapy. Am $\mathcal{F}$ Cardiol 1992;69:733-5.

9 Curtis G, Houghton J, Patterson J, Koch H, Bradley D, Adams K Jr. Propranolol therapy alter estimation of potentional cardiovascular risk derived from sub-maximal exercise testing. Am Heart 7 1991;121:1655-8.

10 Moos A, Prevedel J, Mohiuddin S, Hilleman D, Sketch M Sr. Effect of digoxin on ST-segmen changes detected by ambulatory electrocardiographic monitoring in healthy subject. Am y Cardiol 1991;68:1503-6. 